\title{
Orgulho De Ser Nordestino! Um Estudo Sobre Ethos Compartilhado Por Seguidores Em Uma Página Do Facebook
}

\author{
Proud Of Born In The Northeast: A Study About Shared Ethos By \\ Followers In A Facebook Fanpage
}

\author{
Rafaela Sousa de Oliveira ${ }^{1}$, Minelle Enéas da Silva ${ }^{1}$, Brunno Fernandes da Silva Gaião ${ }^{2}$ \\ ${ }^{1}$ Universidade de Fortaleza, UNIFOR, Brasil, ${ }^{2}$ Universidade Estadual da Paraíba, UEPB, Brasil. \\ Correspondência: Minelle Enéas da Silva. Av. Wasshington Soares, 1321, Edson Queiroz CEP 60.811-905, \\ Fortaleza, CE, Brasil. Telefone: +55 (85) 3477-3000. E-mail: minele.adm@gmail.com.
}

Recebido: 10 de outubro de 2018 Aceito: 19 de novembro de 2018 Publicado: 28 de dezembro de 2018

DOI: http://dx.doi.org/10.21714/1679-18272018v16n2.p182-193

\begin{abstract}
Resumo
O envolvimento de usuários via mídias sociais demonstra aspectos que podem levar a formação de coletividades a partir do conceito de ethos compartilhado. Nesse sentido, este estudo objetiva compreender como o ethos compartilhado dos seguidores da página do Facebook Nação Nordestina se manifesta, sob a perspectiva da Consumer Culture Theory - CCT, em especial falando de cultura de mercado. Para tanto, foi desenvolvida uma pesquisa qualitativa básica por meio de entrevistas com usuários do Facebook que eram seguidores da página estudada. Por meio de uma análise de conteúdo, os resultados demonstram haver uma identificação dos seguidores com a página e com seu administrador. No Facebook, os seguidores interagem com os conteúdos que tanto lhes representam como representam a coletividade da qual fazem parte. O ethos discursivo da página aliado ao ethos prévio do administrador coincidem com a subjetividade dos seguidores manifestando o ethos compartilhado de todos os envolvidos nessa interação. Para a maioria, o seu perfil representa "quem são" e suas vidas. Com esta pesquisa, torna-se claro que no contexto virtual pode ser criado um contexto de ethos compartilhado, uma vez que o enunciado e a reputação da página podem ter a capacidade de representar o indivíduo na sociedade.
\end{abstract}

Palavras-chave: Cultura nordestina, Ethos, CCT, Facebook.

\begin{abstract}
In social media there is the possibility of forming collectivities based on shared ethos. In this context, this study aims to understand how the shared ethos of The Northeast Nation Facebook page followers manifests itself using the Consumer Culture Theory perspective, focused on market cultures. This is a qualitative research carried out using interviews with Facebook users who were followers of the page studied. Using content analysis, was observed an identification with the page and with its administrator among the interviewees. On Facebook, followers interact with the content that represents them and represent the community of which they are a part. The discursive ethos of the page allied to the prior ethos of the administrator coincide with the subjectivity of the followers manifesting the sharing of the ethos of all involved in this interaction. For most, the profile represents who they are, their lives. These followers also believe that there is a representation of the "I myself" through the page and that this social network helps in the spread of the Northeastern culture. Thus, we understand that the interactions between the followers and the page are a means of sharing the ethos of the parties involved in this social network.
\end{abstract}

Keywords: Northeastern culture, Ethos, CCT, Facebook.

Esta obra está licenciada sob uma Licença Creative Commons Attribution 3.0.

\section{Introdução}

Nas últimas três décadas a aplicação de estudos interpretativistas tem ganhado força no que se refere aos estudos do consumo. Na década de 1980, o interpretativismo emerge como corrente paradigmática alternativa à epistemológica positivista dominante. Essa corrente tem como foco a compreensão do consumo, das escolhas 
comportamentais e das práticas sociais dos consumidores enquanto um fenômeno cultural (GAIÃO et al., 2012).

Esses estudos buscam compreender, por exemplo, a apreciação do consumo de bens e serviços que lhes "transportem" a lugares diferentes e lhe ofereçam a possibilidade de experimentar diversidade cultural (SOLOMON, 2011). Há um fluxo de trabalhos interessados em analisar aspectos socioculturais, experienciais, simbólicos e ideológicos do consumo. A produção de pesquisas relacionadas a esses temas despertou a necessidade de um espaço para discuti-los, assim nasceram algumas revistas e eventos específicos para este fim (GAIÃO et al., 2012; PINTO et al., 2016).

Arnould e Thompson (2005), com base em estudos publicados no Journal of Consumer Research, publicaram um artigo que instituía uma nova corrente de pesquisa, chamada Consumer Culture Theory (CCT). A CCT destaca a relação entre contextos culturais e sociais, a construção, a alteração e a distribuição dos significados do consumo (ARNOULD; THOMPSON, 2007). A partir do foco de pesquisas da CCT percebe-se maneiras pelas quais os consumidores criam sentimentos de solidariedade social e criam mundos culturais distintivos, fragmentários, auto selecionados na busca de interesses comuns de consumo. A essas ações dá-se o nome de cultura de mercado, uma forma de explorar o entendimento sobre "como o consumidor consome", com foco na interseção entre mercado e cultura (ARNOULD; THOMPSON, 2005).

Considera-se que os consumidores usam bens e serviços para reafirmar identidade, declarar pertencimento ou não a um grupo, por exemplo (PINTO; LARA, 2011; SOLOMON, 2011). As pessoas, por meio dos bens de consumo, expressam categorias, cultivam ideias, criam e mantém estilos de vida, construindo noções de si e sendo e vivendo as mudanças sociais (McCRACKEN, 2003). É a expressão e produção da cultura concomitantemente, gerando mudanças nas pessoas e na sociedade.

Inserido na temática em questão, encontra-se as chamadas Comunidades de Consumo, que seguindo o estudo de Gaião et al. (2012), são as comunidades formadas em torno da prática de consumo, com destaque para as comunidades de marca e de estilos de vida específicos, especialmente aqueles opostos aos padrões ditados pelas práticas sociais em vigência. Tal noção também aparece em abordagens sobre ethos compartilhado, sentimento de pertença, subculturas, neotribalismo, entre outras.

Nesta pesquisa o foco está no ethos compartilhado, que é possível pela reunião de pessoas com práticas de consumo em comum. Tal grupo pode ser observado em diversos contextos, dentre os quais destaca-se o ethos compartilhado representado por meio das mídias sociais - exemplificado pelos perfis de redes sociais como Facebook, Instagram, Twitter. Neste cenário, o conteúdo compartilhado em uma página de internet pode ser de interesse comum de várias pessoas que reconhecem (no que veem, leem, escutam e/ou assistem) algo com o que se identificam e interagem produzindo novos conteúdos.

Nas mídias sociais há perfis que tratam de assuntos distintos, inclusive aqueles que vão de encontro aos modismos. Ao mesmo tempo que um indivíduo se identifica com as informações de uma página do Facebook (Fanpage), percebe-se também uma oportunidade de ter um representante no que se refere àquele assunto. É ter algo/alguém como seu porta-voz, o que reduz o risco de exposição da própria "fala", afinal, a autoria do conteúdo é de outra pessoa. Assim emerge o ethos compartilhado que se refere à construção da identidade por meio do desejo da comunhão dos valores e imagens reconhecidos no discurso do outro (RECUERO, 2014; SOLOMON, 2011; PEREIRA, 2016).

Com base na discussão já apresentada, de acordo com Pereira (2016), ao curtir ou compartilhar algum conteúdo no Facebook emerge um ganho múltiplo de ethos. O proprietário do perfil, ao fazer as postagens, recebe feedback dos seguidores por via das reações que o site disponibiliza. É a manifestação da identificação ou não das pessoas com o que está sendo expresso naquela página. Eles podem ser oriundos da associação com o conteúdo (ethos discursivo), da associação com o ator-detentor (ethos prévio) e da associação de todos os atores envolvidos (ethos compartilhado) derivado do ethos de todos os indivíduos em rede.

Nesse sentido, para esta pesquisa toma-se como foco a página Nação Nordestina, que foi criada em 2011 pelo cearense Bráulio Bessa e recebeu o prêmio de maior movimento virtual de divulgação da cultura nordestina no mundo (FACEBOOK, 2016). O conteúdo tem um caráter predominantemente regionalista e é publicado em formatos variados, como textos, imagens, notícias e vídeos, todos relacionados aos Estados da região Nordeste do Brasil (SALES, 2015).

Com base nessas informações, entende-se que as redes sociais surgem como um espaço de expressão de subjetividade, nelas a cultura é representada na interação dos seguidores nas postagens que transmitem hábitos, linguagem, culinária ou a vestimenta daquele povo. O simbolismo presente no olhar dos seguidores os faz ter reações que são relativas à sua subjetividade (ADERALDO, 2016). Diante disto, surge o questionamento norteador desta pesquisa: Sob a perspectiva da CCT, como se manifesta o ethos compartilhado dos seguidores da página do Facebook Nação Nordestina? 
Este trabalho justifica-se pela proposta de estudar o papel do consumo para além do ato da compra como uma condição básica. Deve-se levar em conta que os consumidores utilizam bens e serviços para dizer algo sobre si mesmos, reafirmar suas identidades, definir sua posição no espaço social, ou mesmo declarar seu pertencimento a um ou outro grupo (PINTO; LARA, 2011). Além disto, buscou-se contribuir para a melhor compreensão do papel das mídias sociais na formação e interação dos indivíduos enquanto consumidores, cenário que tem se estabelecido de forma cada vez mais marcante, graças aos avanços e difusão da tecnologia.

\section{Consumer Culture Theory (CCT), Culturas de Mercado e Subculturas}

O consumo é resultante das mudanças sociais, econômicas e culturais. Já os bens de consumo são caracterizados como o "lócus" dos significados culturais de determinado contexto social, ou seja, os bens têm uma representação em cada contexto que os abriga (McCRAKEN, 2003). Com esta visão, entende-se que o consumo é uma manifestação simbólica que se caracteriza pela interação entre bens e indivíduos e, como tal, uma forma privilegiada de ler o mundo que nos cerca. Existe significado atrelado aos bens de consumo, isso deve ser identificado pelo consumidor. Há de haver um alinhamento entre a mercadoria e o indivíduo que irá consumi-la, é ele quem reconhece essa relação. $\mathrm{O}$ uso de imagens, som e fala são importantes, no instante em que remetem à lembrança e a comunicação com as pessoas (MCCRAKEN, 2003).

Uma cultura de consumo pode englobar subculturas, porém ela é em si, o palco capitalista para o consumo por intermédio de símbolos e significados (SEGABINAZZI, 2015; SLATER, 2002). Quando o símbolo e a simbologia se encontram, o consumo ganha um largo espaço que se fragmenta de acordo com as semelhanças e diferenças. A partir disso, grupos são formados e o mercado perpetua esse ciclo. Pesquisar contextos específicos oportuniza estudar como conceitos podem atuar em situações extremas, destaca pontos de contato de conceitos distintos ou, ainda, auxilia a explicitar fronteiras de como, onde e dentro de que situações as teorias se aplicam. É característico da CCT, tornar evidente as singularidades de um contexto relacionando sua conexão com fenômenos similares de outras realidades (CASOTTI; SUAREZ, 2016).

A CCT abre espaço para pesquisadores que investigam o contexto brasileiro realçarem as singularidades culturais deste país, ao passo que podem ser úteis a um contexto universal para despertar o interesse e mobilizar leitores brasileiros, norte-americanos ou europeus. O Brasil é um país emergente com contexto relevante por suas características históricas e sociais que edificam uma construção multicultural, de convivência e miscigenação de diferentes etnias (CASOTTI; SUAREZ, 2016; PINTO et al., 2016).

A partir da formação de padrões sócio-históricos de consumo, pode-se perceber a relação entre as experiências, sistemas de crenças e práticas dos consumidores com as estruturas de base social e institucional. No ambiente externo há a interação entre instituições de economia global e as culturas e economias locais formando as culturas de mercado ou culturas de consumo (SOUZA et al., 2013)

$\mathrm{Na}$ fronteira de oposição aos estilos de vida dominantes os consumidores buscam interesses comuns de consumo. Contrariando a visão antropológica tradicional, os consumidores são agora, produtores de cultura e não portadores dela. É pelo consumo que ele demonstra isso. Os consumidores forjam identificações coletivas e participam de rituais de solidariedade que tem como fundamento os interesses comuns de lazer e estilos de vida (SOUZA et al., 2013). Esta pesquisa concentra-se em debater sobre esta linha.

\subsection{Culturas De Mercado E Subcultura}

McCracken-Flesher (2007) diz que os significados compartilhados são responsáveis por estabelecer o mundo ao nosso redor. A cultura constrói o mundo. E neste processo são estabelecidos também os significados destinados aos bens de consumo. Os bens são a oportunidade de materializar uma cultura. Como qualquer tipo de cultura material, os bens possibilitam que os indivíduos discriminem visualmente as categorias culturalmente especificadas, traduzindo essas categorias com um "pacote" de distinções materiais (MCCRACKEN, 2003).

Para Arnould e Thompson (2005), as culturas de mercado trazem a representação do consumidor como "produtor de cultura" e não somente como um ser que absorve cultura, como se pensava em teorias anteriores. Segundo os autores, as mudanças provocadas pela industrialização no mundo e da globalização, tiveram um papel decisivo na busca dos consumidores por diferenciação e autonomia em suas escolhas de estilos de vida (ALBINO et al., 2010). De acordo com Barbosa (2004, p. 11), aqui investiga-se como o "consumo se conecta com outras esferas da experiência humana e em que medida ele funciona como uma 'janela' para o entendimento de múltiplos processos sociais e culturais".

Arnould e Thompson (2005) definem cultura de mercado quando afirmam que consumidores modelam sentimentos de solidariedade social e constroem mundos culturais distintos, fragmentados, autoselecionados por 
meio da busca por interesses de consumo em comum. Para Gaião et al. (2012), as culturas de mercado ditam suas fronteiras simbólicas por meio de uma postura contrária contínua às regras do estilo de vida dominante.

Vestuário, transportes, alimentos e adornos residenciais atuam como meio para a expressão do significado cultural que constitui nosso mundo. $\mathrm{O}$ fato de os bens possuírem significado cultural é algumas vezes perceptível e às vezes não tão explícito para os consumidores. Estes podem perceber e manipular conscientemente significados culturais como o status de um item de consumo (MCCRACKEN-FLESHER, 2007).

Neste contexto, cabe ressaltar que cultura de mercado e subcultura apresentam definições semelhantes. Shouten e McAlexander (1995) definem subcultura de consumo como um subgrupo distinto da sociedade que se autosseleciona com base em um compromisso compartilhado com uma marca, classe de produto ou atividade de consumo. Outras características de uma subcultura de consumo incluiriam uma estrutura hierárquica identificável, um ethos (conjunto de atitudes, crenças e valores) único, além de rituais, linguagem e modos de expressão simbólica únicos (SEGABINAZZI, 2015).

Beal e Crosset (1997), ao analisarem trabalhos em antropologia e esportes, desde os anos 1970, afirmam que uma subcultura é caracterizada pelo compartilhamento de ideais, valores, estilos de vida e linguagem de um grupo, e esse grupo necessariamente deve ser visto como diferente do restante da sociedade, ou de uma "grande cultura" (SEGABINAZZI, 2015). Solomon (2004) define uma subcultura como um grupo cujos membros compartilham crenças e experiências comuns que as diferenciam dos demais membros de uma cultura.

As definições de Beal e Crosset (1997) e Solomon (2004) diferenciam-se, aparentemente, da definição de subcultura de consumo, pois, além de não abordarem diretamente a questão do consumo, trazem como elemento importante a necessidade de reconhecimento do subgrupo como diferente dos demais membros de uma cultura. É importante diferenciar também uma subcultura de uma contracultura. Mais do que o compartilhamento de ideais e crenças, os elementos de uma contracultura se unem por uma posição contrária ao sistema vigente (SEGABINAZZI, 2015).

Na visão de Holt (1997), os estilos de vidas são construídos coletivamente e não pelos sujeitos individualmente. Estes se identificam com algum estilo de vida que emergiu em sua época e lhe confere uma performance particular, coerente com sua trajetória pessoal e estrutura de personalidade (ALBINO et al., 2010).

Vários estudos têm buscado entender a maneira como os bens agem nessa materialização. O estudo de Sahlin (1976) sobre o simbolismo dos bens de consumo norte-americanos examina os "sistemas" de alimentos e vestuário, é um exemplo que mostra sua relação com categorias culturais das pessoas. Estudos apresentam que a ordem dos bens está estreitamente ligada e se molda a partir da ordem da cultura. Boa parte do significado dos bens pode ter sua origem nas categorias em que uma cultura segmenta o mundo (MCCRACKEN, 2003). O simbolismo pode ser detectado a partir da representação das crenças, valores e atitudes.

É importante ressaltar que a cultura está em constante evolução e misturando ideias e práticas antigas e novas. Parte-se da ideia que membros de uma sociedade comungam uma visão de mundo em comum. Compartilham também princípios morais, estéticos e um ethos (SOLOMON, 2011). Esta pesquisa enfatiza o debate sobre ethos compartilhado e, especialmente, no que se refere ao ambiente virtual.

\section{Ethos Compartilhado}

Os conceitos de ethos perpassam por alguns pensadores em épocas diversas como, por exemplo, Aristóteles que compreendia ethos como a imagem de si construída no discurso, ou os romanos, que fundamentam-se em dados preexistentes como a reputação da família, o que se sabe a respeito do modo de vida do orador. Na arte da oratória romana, inspirada mais em Isócrates (436-338 a.C.) que em Aristóteles, o ethos pertence à esfera do caráter. Alguns pensadores afirmam que a própria vida de um homem tem mais peso que suas palavras e que definem o bom orador como um indivíduo que é capaz de aglutinar ao caráter moral a capacidade de bem manejar o verbo (AMOSSY, 2005).

Em espaços onde há uma audiência, um discurso e um enunciador, há a eminência do ethos prévio (caráter/reputação do orador esperado pela plateia) e do ethos discursivo (o enunciado). Quando há convergência de valores, diz-se que há um compartilhamento do ethos.

A aparição perante o outro é que faz com que os homens desenhem sua identidade pessoal (FROCHTENGARTEN, 2005). Para os antigos o termo ethos era entendido como a edificação de uma imagem de si com o objetivo de garantir que o pronunciamento do orador lograsse êxito. Há autores que compreendem o ethos como a exibição dos principais indicadores de caráter à audiência por parte do orador (sendo isso sincero, ou não) no intuito de transmitir uma boa imagem: é o modo de ser do orador. Ao mesmo tempo que ele enuncia uma informação ele também informa ao auditório o que, e quem ele é (AMOSSY, 2005). 
O caráter e a corporalidade dado pela audiência é oriundo de um conjunto difuso de representações sociais com determinado significado (valorizadas ou não por eles) e que sustentam ou não a enunciação. Essa subjetividade contida na audiência é que define o valor atribuído ao enunciado (PALÁCIOS, 2004). É nessa corrente que esta pesquisa se apoia.

Estilo, competências linguísticas e enciclopédicas, crenças implícitas constroem a representação de sua pessoa. Ao elaborar um discurso, conscientemente ou não, o locutor realiza uma apresentação de si. É inquestionável que a forma de falar induz a uma imagem. Isso pode ser a condição central para a realização de um projeto e é fundamental considerar as consequências disso (AMOSSY, 2005).

No tocante à legitimação do ethos, ela depende da audiência a quem foi destinada a imagem construída. É essa audiência que quer corroborar por meio do discurso do orador, a imagem pré-concebida que tem dele. A prática, no que tange ao ethos, não é consciente. É a maneira de dizer remetendo a maneira de ser do sujeito (FERNANDES, 2011).

A interação é condição básica para a concretização da legitimação por parte do "outro". A cumplicidade do interlocutor, nessa interação, valida a identidade e os papeis representados (RIBEIRO, 2003). O consumo do discurso/ethos de alguém dá ao enunciador um ganho. As interações possibilitam manter laços sociais, ganho relacional que são contabilizados como capital social (PEREIRA, 2016; RECUERO, 2014).

$\mathrm{Na}$ fala, pode surgir a presença de sentimentos para referir-se a produtos. A expressão "eu amo isso" é um exemplo de como os consumidores transparecem apreço e conexão com produtos. A cultura se revela com um papel importante na interpretação, construção e funcionamento dos sentimentos (FLEMING, 2015). Sentimentos, cultura e ethos somados, são reflexos da subjetividade humana.

Outra possibilidade de emergir o ethos é o desejo de corporificá-lo e assimilar o capital social de alguém que tem um perfil em uma rede social. Isso fica evidente quando o indivíduo deseja fazer parte do mesmo grupo social que o enunciador, por exemplo. Nestes espaços, constroem-se novas formas de sociabilização, em um aprendizado da linguagem corporal representada, ali, pelos perfis individuais (GOFFMAN, 1985).

Os atores envolvidos em uma interação buscam transmitir uma imagem aos interlocutores e fazê-los acreditar que ela existe. Analogamente, é o que acontece em sites de redes sociais com a construção do ethos a partir da postagem de imagens, links, vídeos ou textos, apontando os gostos e o valor atribuído a cada comportamento, atitude ou escolha apresentados pelo conteúdo posto em público (CARRERA, 2012).

\section{Procedimentos Metodológicos}

Conforme as palavras de Saccol (2009), no que tange a epistemologia e paradigma de pesquisa, este estudo enquadra-se em uma epistemologia construtivista, ficando evidente a construção dos significados através da interação social e da intersubjetividade. O paradigma ao qual esta pesquisa faz parte é o interpretativista, visto que os resultados são oriundos da interpretação do pesquisador sobre a interpretação dos entrevistados a respeito do fenômeno em questão. O que importa para o interpretativismo são os significados subjetivos, bem como as ações simbólicas na construção e reconstrução da realidade das pessoas (DENZIN; LINCOLN, 2005; LINCOLN; GUBA, 2006; SACCOL, 2009).

Para esta investigação privilegia-se o método qualitativo que se preocupa em descrever os fenômenos por meio dos significados que o ambiente manifesta, expressando os resultados na forma de transcrição de entrevistas, documentos, diários pessoais, fotografias, declarações, desenhos dentre outras formas de coleta de dados e informações (ZANELLA, 2009).

A pesquisa qualitativa é usada quando se deseja compreender o significado dos acontecimentos e interações para os indivíduos em eventos particulares (SILVA et al., 2011), portanto, apresenta-se como a abordagem mais coerente com o objetivo de compreender qual a influência do ethos compartilhado no consumo de conteúdo da página do Facebook Nação Nordestina, com base na CCT. Além disso, preocupou-se em descrever os fenômenos por meio dos significados que o ambiente manifesta, expressando os resultados na forma de transcrição de entrevistas, imagens, declarações, dentre outras formas de coleta de dados e informações (ZANELLA, 2009)

\subsection{Construção Do Corpus De Pesquisa}

O objeto de pesquisa envolve o ambiente virtual da página Nação Nordestina. Em contato inicial com o idealizador e administrador da página algumas informações foram repassadas. Em 2016, por e-mail, Bráulio Bessa disse que a página Nação Nordestina foi criada em 2011 por ele, poeta e escritor e que o objetivo da Fanpage é valorizar a cultura da região Nordeste por meio das redes sociais. 
Para melhor compreensão do fenômeno de manifestação do ethos compartilhado dos seguidores da página Nação Nordestina no Facebook, foi necessário contatar os seguidores da página. Como estratégia de pesquisa, utilizouse a técnica de entrevista apoiada por um roteiro semiestruturado. O roteiro de entrevistas deve ser um instrumento flexível exercendo o papel de norteador e precisa ser revisto frequentemente no intuito de saber se ele ainda atende aos objetivos da pesquisa (DUARTE, 2002).

De acordo com Zanella (2009), entrevista é a técnica mais indicada quando se quer obter informações referentes a opiniões que envolvem sentimentos, comportamentos, além de oferecer maior liberdade no diálogo entre o entrevistador e o entrevistado. Os critérios de seleção dos respondentes foram: 1) ser seguidor da página do Facebook Nação Nordestina a mais de um ano; 2) ter interagido na página nos últimos 03 meses (do momento da pesquisa). Um total de 16 (dezesseis) seguidores fizeram parte da pesquisa (Quadro 01). As entrevistas foram agendadas e mediadas tanto por computador (via Skype, Facebook Messenger, vídeo chamada pelo Whatsapp ou ligação telefônica) quanto por meio de entrevista face a face, de acordo com a acessibilidade dos entrevistados.

A partir do momento que as entrevistas chegaram em um ponto de saturação, chegou o fim da coleta dos dados. Conforme Fontanella et al. (2011), a coleta dos dados deve ser interrompida quando o pesquisador percebe a ausência de novas informações, provenientes do campo, que deem suporte para construir a teoria que se pretendia não são mais depreendidos a partir do campo de observação.

Quadro 1: Caracterização dos entrevistados

\begin{tabular}{|l|l|l|l|}
\hline Numeração Indicativa & Gênero & Idade & Profissão \\
\hline S1 & Feminino & 29 anos & Professora universitária. \\
\hline S2 & Masculino & 28 anos & Empresário. \\
\hline S3 & Feminino & 30 anos & Bióloga \\
\hline S4 & Feminino & 24 anos & Turismóloga \\
\hline S5 & Feminino & 23 anos & Estudante. \\
\hline S6 & Masculino & 23 anos & Turismólogo \\
\hline S7 & Feminino & 30 anos & Comerciante. \\
\hline S8 & Feminino & 27 anos & Auxiliar de contabilidade. \\
\hline S9 & Feminino & 21 anos & Empresária. \\
\hline S10 & Feminino & 27 anos & Maquiadora. \\
\hline S11 & Masculino & 20 anos & Auxiliar de contabilidade. \\
\hline S12 & Feminino & 29 anos & Administradora. \\
\hline S13 & Feminino & 25 anos & Psicóloga. \\
\hline S14 & Masculino & 29 anos & Empresário. \\
\hline S15 & Feminino & 39 anos & Administradora. \\
\hline S16 & Feminino & 31 anos & Bancária. \\
\hline
\end{tabular}

Fonte: Dados de pesquisa (2017).

As informações coletadas com esses sujeitos, compuseram o corpus da pesquisa e foram utilizados para o desenvolvimento das análises.

\subsection{Procedimentos De Análise}

Após a coleta de dados foi realizada a análise por meio da análise de conteúdo. Nesta técnica de análise, o pesquisador categoriza o texto (ferramenta de expressão do entrevistado) em palavras ou frases e faz inferências representativas. Essa categorização é feita com base na similaridade que os agrupa (CAREGNATO; MUTTI, 2006). É com base nesse agrupamento que se pode inferir os significados relacionados ao objetivo em questão.

A análise de conteúdo busca realizar um "tratamento da informação contida na mensagem" (BARDIN, 2011, p. 41). Ela "é considerada uma técnica para o tratamento de dados que visa identificar o que está sendo dito a respeito de determinado tema" (VERGARA, 2012, p. 7). O intuito é compreender o significado que a mensagem guarda e isso é possível utilizando esta técnica. Para esta pesquisa foram identificadas 03 (três) categorias que emergiram das falas, mas foram criadas também considerando a literatura estudada (Quadro 02). As categorias são: Culturas de Mercado, Percepção da cultura nordestina e Ethos.

Quadro 2: Categorias de análise.

\begin{tabular}{|l|l|}
\hline Categorias & Descrição \\
\hline $\begin{array}{l}\text { Percepção da cultura } \\
\text { nordestina }\end{array}$ & $\begin{array}{l}\text { Categoria que demonstra o local de nascimento, como é a relação dos entrevistados } \\
\text { com o Nordeste e que elementos representam a região. Busca-se a partir dessas } \\
\text { respostas, compreender como eles percebem a cultura nordestina. }\end{array}$ \\
\hline Culturas de Mercado & Esta categoria demonstra os aspectos de identidade e Representação do Eu nos \\
\hline
\end{tabular}




\begin{tabular}{|l|l|}
\hline & conteúdos postados na página. \\
\hline Ethos & $\begin{array}{l}\text { Busca entender como a subjetividade dos seguidores os fazem ou não Fãs e se há } \\
\text { engajamento. }\end{array}$ \\
\hline
\end{tabular}

De forma complementar, a Quadro 3 apresenta a descrição de cada uma das subcategorias que foram identificadas e fazem parte das análises da pesquisa.

Quadro 3: Subcategorias de análise.

\begin{tabular}{|c|c|}
\hline Subcategorias & Descrição \\
\hline Local de nascimento & $\begin{array}{l}\text { Subcategoria oriunda da categoria de percepção da cultura nordestina. Tem o intuito } \\
\text { de caracterizar os entrevistados com relação a naturalidade. }\end{array}$ \\
\hline $\begin{array}{lll}\text { Relação } & \text { com } & \\
\text { Nordeste } & & \\
\end{array}$ & $\begin{array}{l}\text { Proveniente da categoria de percepção da cultura nordestina. Refere-se ao } \\
\text { contato/vínculo dos entrevistados com a região Nordeste. }\end{array}$ \\
\hline $\begin{array}{ll}\text { Elementos } \\
\text { representam }\end{array} \quad$ que & $\begin{array}{l}\text { Última subcategoria de Percepção da cultura nordestina e identifica os bens tangíveis } \\
\text { e/ou intangíveis que, na opinião dos entrevistados, representa o Nordeste. }\end{array}$ \\
\hline Conteúdo postado & $\begin{array}{l}\text { Subcategoria proveniente de Culturas de Mercado. Trata do significado atribuído } \\
\text { pelos entrevistados, aos conteúdos apresentados na página. }\end{array}$ \\
\hline Aspectos da identidade & $\begin{array}{l}\text { Subcategoria oriunda de Culturas de Mercado e que revela os aspectos percebidos } \\
\text { pelos seguidores entrevistados como próprios de sua identidade. }\end{array}$ \\
\hline Representação do Eu & $\begin{array}{l}\text { Subcategoria das Culturas de Mercado que revela se a página representa ou não os } \\
\text { seguidores. }\end{array}$ \\
\hline Engajamento & $\begin{array}{l}\text { Subcategoria oriunda da categoria Ethos. Busca saber o que faz com que os } \\
\text { entrevistados interajam com a página. O que tem na página que leva os seguidores a } \\
\text { curtir, compartilhar, comentar ou reagir nas postagens. }\end{array}$ \\
\hline Fãs & $\begin{array}{l}\text { Subcategoria que é consequência do Ethos. Revela a assiduidade do contato entre os } \\
\text { seguidores e a página. }\end{array}$ \\
\hline
\end{tabular}

\subsection{Critérios De Qualidade Da Pesquisa}

Quando o pesquisador, na reflexão crítica, torna explícitos os critérios utilizados para guiar e avaliar a pesquisa há um ganho de credibilidade e legitimação externa do estudo. Para que tenha qualidade, a análise deve transmitir confiança para que se chegue a conclusões corretas, além de permitir que no momento que se queira realizar pesquisa semelhante, o resultado será muito aproximado (PAIVA JUNIOR et al., 2011). Este trabalho se valeu como critério de qualidade a própria construção do corpus de pesquisa, a descrição rica e detalhada dos dados de pesquisa, a triangulação da análise de pesquisadores (PAIVA JUNIOR et al., 2011). Para tanto, houve validação interna na medida em que os dados foram debatidos e analisados em conjunto pelos pesquisadores.

\section{Resultados e Discussão}

\subsection{Lócus De Pesquisa}

A escolha do Facebook para estudo se deu pela relevância desta mídia social. De acordo com dados da Pesquisa Brasileira de Mídia (PBM), 92\% dos internautas no país têm acesso a mídias sociais. Dentre os brasileiros que fazem uso das mídias sociais, $83 \%$ acessam o Facebook, 58\%, o WhatsApp e 17\%, o Youtube (BRASIL, 2014). O Facebook anunciou que entre seus usuários, mais de 92 milhões são brasileiros, ou seja, $45 \%$ da população do país faz uso desta mídia (FACEBOOK, 2015).

Nas redes sociais, especificamente no Facebook, há a clara presença do ethos. É um espaço de expressão de um enunciador (dono do perfil) onde há uma plateia (seguidores) e o ethos emerge nessa relação. Curtir ou compartilhar algo de alguém representa ganho múltiplo de ethos. Isso acontece pela associação de quem interage, com o conteúdo (ethos discursivo), com seu ator-detentor (ethos prévio) e da associação entre os personagens envolvidos nessa interação (ethos compartilhado) (PEREIRA, 2016). Um indivíduo enuncia algo, fundamentado em seu ethos e os espectadores interagem de algum modo, com o mesmo fundamento.

Ao reagir - representando emoções - utilizando as opções ofertadas pelo site, os seguidores estão informando sua adesão aquele conteúdo. Para a página e seu administrador é uma confirmação de que as pessoas reunidas naquela comunidade identificam-se com algo presente na fanpage. Fanpage ou Página de fãs é uma página específica dentro do Facebook voltada para empresas, marcas ou produtos que busquem interagir com os seus clientes nesta mídia. 
O objeto de pesquisa envolve o ambiente virtual da página Nação Nordestina. Em contato inicial com o idealizador e administrador da página algumas informações foram repassadas. Bráulio Bessa afirma que desde o início do projeto, dedica cerca dez horas diárias à produção de conteúdo que valorize a cultura nordestina, e que usa principalmente a página Nação Nordestina para isto. Na época a página já tinha mais de 1 milhão de fãs e também já era considerada o maior movimento virtual em defesa da cultura nordestina no mundo.

O criador da página disse ainda que sempre foi apaixonado por cultura nordestina, poeta cordelista desde os 14 anos, e sentia muita falta de uma ferramenta onde o próprio povo - sem depender dos meios de comunicação tradicionais - pudesse divulgar sua cultura local, assim, identificou nas redes sociais uma ferramenta democrática e forte para fazer a cultura popular nordestina romper qualquer barreira.

O projeto que nasceu em uma cidade de apenas 18 mil habitantes no sertão do Ceará (Estado da região Nordeste do Brasil) chamada Alto Santo. O administrador diz que atualmente, a página causa impacto social e cultural em mais de 20 milhões de pessoas por mês, promovendo um verdadeiro resgate da cultura e da autoestima do povo nordestino. Abaixo, segue imagem da página inicial da Fanpage.

Figura 1: Página inicial da Fanpage Nação Nordestina.

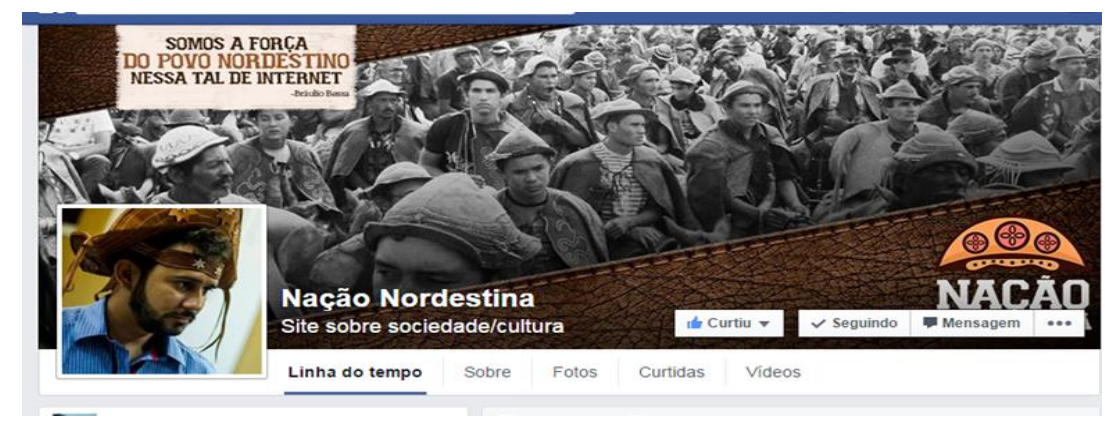

Fonte: Dados de Pesquisa (2017).

A adesão das pessoas a este conteúdo fica clara pela quantidade de interações, das diferentes formas, que surgem. Os aspectos estéticos colaboram para o resgate da memória relacionada a postagem e impulsionam a audiência a interagir com aquele conteúdo. Isso acontece nos demais posts que seguem.

Conforme o que Bráulio Bessa afirmou, a tecnologia - principalmente as novas mídias sociais - são vistas com olhos tortos por grande parte dos defensores da cultura popular que acusam muita vezes de ser uma espécie de vilã por causar um certo afastamento da juventude em relação a suas raízes. Neste caso, ele identificou uma maneira de usar o "inimigo" a favor de uma causa, e tanto o tema quanto a ferramenta usada foram importantes para o crescimento e reconhecimento do projeto em questão.

\subsection{Percepção Dos Seguidores Sobre A Cultura Nordestina}

Para iniciar a compreensão sobre a percepção de seguidores em uma mídia social, pode se apoiar no pensamento que segue. Recuero (2014) diz que os atores têm consciência sobre as impressões que desejam gerar e dos valores e impressões que podem ser edificados nas redes sociais mediadas por computador. Devido a isso, é provável que os conteúdos que escolhem postar sejam, de maneira direta, influenciados pela percepção de valor que poderão gerar.

Passando para a análise da categoria Percepção da cultura nordestina, primeiro mapeou-se o local de nascimento dos seguidores entrevistados em seguida emergindo as subcategorias Relação com o Nordeste e Elementos que representam a região. A partir do local de nascimento, os entrevistados afirmam que começa suas relações com o Nordeste. São 14 (Quatorze) piauienses, dos quais 01 (um) de Simplício Mendes, 01 (um) de Corrente, 01 (um) do interior de Bom Princípio, e 11 (onze) de Parnaíba. Além disso, há 01 cearense de Fortaleza e 01 (um) de Brejo no Maranhão.

Continuando a relação dos entrevistados com o Nordeste, nas falas dos entrevistados, fica claro uma relação de sentimentos como: Admiração, apego, eternidade, orgulho, paixão e amor, por exemplo. Dos dezesseis entrevistados, oito relatam o sentimento de paixão e amor pelo Nordeste. No estudo do comportamento do consumidor, é frequente o aparecimento deste tipo de relação, conforme afirma Fleming et al. (2015). Os mesmos autores dizem ainda que o sentimento de amor ajuda a descrever emoções dos consumidores.

Depois de discorrer sobre a relação dos seguidores com o Nordeste, buscou-se identificar elementos que representam a percepção que eles têm sobre a cultura nordestina. Nessa revelação de subjetividade, surge com destaque a diversidade cultural, incluindo o jeito de falar/sotaque, as belezas naturais, a hospitalidade do povo 
acolhedor e a culinária.

Figura 2: Comentários em postagem de cordel.

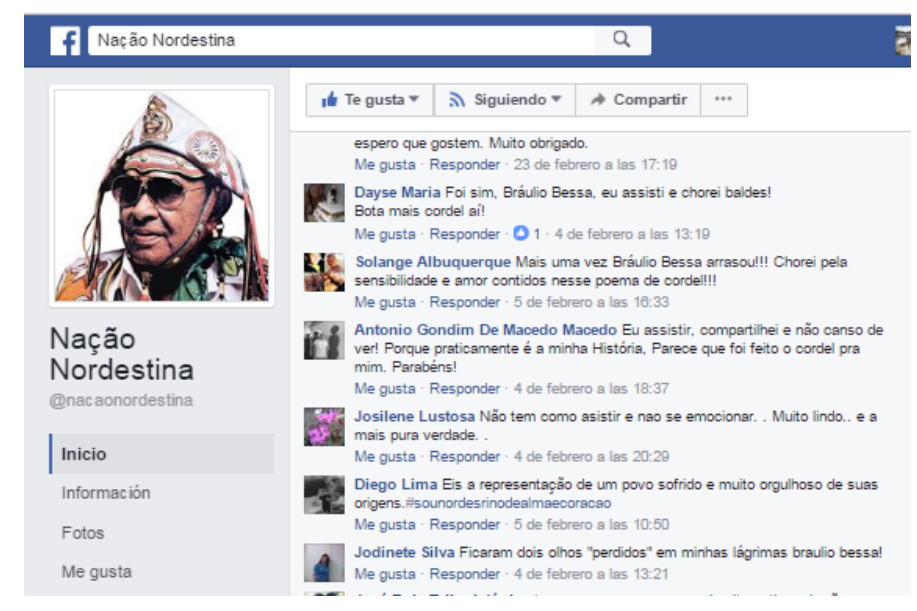

Fonte: Dados de Pesquisa (2017).

Pelos comentários e relatos dos seguidores entrevistados, fica evidente a comunhão de valores e identificação entre a página e seus seguidores. É nesse sentido que o ethos compartilhado se manifesta. Ao utilizar a ferramenta Comentar, por exemplo, os seguidores dão um aval que o discurso está chegando até eles e que estão de acordo. Isso se manifesta pela escrita, numa interação sem contato físico, mas que gera uma relação de representação e identidade, conforme o que diz as falas na Figura 2.

\subsection{A Expressão Da Subjetividade Dos Seguidores}

No quesito subjetividade, de acordo com Ortner (2007), pode-se entender como o conjunto de modos de percepção, afeto, pensamento, desejo, medo, que tem ação sobre os atores em questão. São aspectos não tangíveis que influenciam as pessoas e seus atos. Para compreensão deste tópico, sobre a subjetividade, serão trabalhadas as subcategorias oriundas da categoria Culturas de Mercado, a saber: Conteúdo postado, Aspectos da Identidade e Representação do Eu.

Notou-se na subcategoria Conteúdo postado que a subjetividade dos seguidores referente às postagens, está atrelada a diversos aspectos materializados. Esses significados podem ser desde músicas, comidas até a identificação com este conteúdo e autorepresentação. A partir da análise, aponta-se que a subjetividade dos seguidores sobre a cultura nordestina está atrelada a costumes, comidas, cultura, expressões/sotaque e lugares, por exemplo. McCracken-Flesher (2007) sustenta esses relatos quando fala sobre transportes, alimentos, e adornos residenciais atuando como meio para a expressão do significado cultural que constitui nosso mundo. Isso significa que bens carregam uma simbologia que tem seu valor dependente de quem o possui. Esse significado cultural é algumas vezes perceptível e às vezes não tão explícito para os consumidores.

Aspectos intangíveis sobressaltaram na fala dos respondentes quando afirmam sentirem-se representados, bem como suas realidades. $\mathrm{O}$ mesmo é dito no que se refere às formações culturais e sociais que modelam, organizam e provocam aqueles modos de afeto e pensamento. O sentimento de amor e a simplicidade, por exemplo, que aparecem nas falas dos respondentes trazem, em seus significados, a essência da subjetividade (ORTNER, 2007).

Ainda no quesito da subjetividade dos seguidores, é importante tratar dos Aspectos da identidade. Esta subcategoria surgiu quando os respondentes expressaram o que de suas identidades, está presente na página.

Identidade é uma parte importante do auto-conceito. Para Stone (1981, p. 188), a identidade é estabelecida no instante em que emerge uma "determinada coincidência de posicionamentos e anúncios". A auto representação individual e em grupo faz parte do conceito de identidade, segundo Oliveira et al. (2012). Auto-conceito é a totalidade de uma pessoa de pensamentos e sentimentos em referência a si mesmo como um objeto (ROSENBERG, 1986), e de identidade é que parte do eu "pelo qual somos conhecidos por outros" (ALTHEIDE, 2000, p. 2).

Arnold e Thompson (2005) entendem o indivíduo como produtor de cultura e não apenas como detentor dela. Essa é uma das premissas que sustentam o conceito de cultura de mercado e que está nítida na fala de S1: "Os aspectos que mais, que eu mais me identifico são: a questão da transformação de tudo em arte. é... dele colocar essa expressividade com senso de humor, né?!". 
$\mathrm{Na}$ fala de S10: "Ela representa um pouco da identidade da gente, tanto em forma de, de, de...ai!... Mas assim, em forma de humor, em forma de poesia, sabe?!" (S10) a identificação está nítida por meio do humor e da poesia. Em uma via de mão dupla, compreende-se que os seguidores identificam-se com o bem (Fanpage) ao passo que o administrador da página expõe seu ethos por meio da produção de cultura, como a escrita da poesia, conforme Belk (1988) diz. As falas informam sobre a identificação e representação do Eu com o conteúdo postado e isso passa pela subjetividade de cada um. Cabe continuar a discussão para melhorar a compreensão de outros aspectos envolvidos.

\subsection{Ferramentas Utilizadas Pelos Seguidores Para Legitimação Do Ethos Compartilhado}

Dentro da categoria Ethos, destacam-se as subcategorias Engajamento e Fãs. Na subcategoria Engajamento notouse que alguns participantes curtem, compartilham e/ou reagem a postagens referentes ao proprietário da página e as poesias que ele produz e recita. Nesse sentido, surgiu a subcategoria "Fã", que busca clarear esse vínculo entre a página e os seguidores. Partindo disso, algumas falas sugerem outros tipos de relação que ainda não seria o conceito de "fã" (alguém que acompanha assiduamente algo), tais como admirador e simpatizante. No mais, onze, dos dezesseis, entrevistados caracterizam-se como fãs.

Diante das respostas, percebe-se uma relação com a página a partir da representação percebida pelos seguidores no conteúdo postado. Os aspectos subjetivos do discurso presentes na página e no administrador (Em S8, a relação extrapola a página e chega até ele), conforme as respostas coletadas deixam claro que a interação é fruto da compatibilidade cultural e do sentimento de ser representado. Há, nesse instante, um compartilhamento do ethos, em que os seguidores "agarram" a expressividade do outro como se fossem eles os emissores do discurso.

A manifestação do ethos se dá na escolha de pertencer àquele grupo e compartilhar do que lá é postado. No uso da linguagem que o administrador faz, por exemplo, o ethos dele se manifesta. Os seguidores sentem representação no humor, nas expressões e interagem de algum modo. Ao utilizar o botão de reações e/ou comentar, os seguidores indicam a influência daquela postagem sobre a subjetividade deles. É o encontro do ethos exposto na página pelo enunciador com o ethos de quem é audiência.

Segundo Amossy (2005) o ethos permite a adesão aos valores comungados por um grupo social dominante, que os faz passar por indiscutíveis. É no discurso (nesse contexto, entendido como as postagens) que os seguidores confirmam ou não as expectativas baseadas no ethos prévio. Em suma, a união do ethos prévio com o ethos discursivo contido na página e a interação oriunda do ethos dos seguidores configura-se na manifestação do ethos compartilhado.

\section{Considerações Finais}

Inicialmente esta pesquisa apresentou-se como proposta de disseminar os estudos de consumo e cultura com base na CCT. Em seguida, acrescentou-se o conceito de ethos compartilhado na página do Facebook Nação Nordestina. Por meio das análises, foi possível identificar a manifestação do ethos compartilhado dos seguidores da página. A cultura no consumo do conteúdo postado, bem como da persona do administrador da página tornou evidente a expressão da subjetividade dos seguidores que formam uma rede onde compartilham valores. Quando há a identificação de um grupo de pessoas no processo de interação social, pode-se chamar de ethos compartilhado.

Com esse trabalho, pode-se entender que as tantas perspectivas oferecidas pela CCT, são fontes para realizar mais pesquisas que relacionem consumo e cultura. Essas pesquisas seguem um paradigma interpretativista e a própria família de perspectivas teóricas (CCT) ainda é recente no Brasil, portanto, há oportunidades para o desenvolvimento de mais trabalhos de pesquisa. Com os resultados, percebe-se que o campo do marketing pode receber contribuições no que se refere a valores, identidade, sentimentos etc., e ainda instigar o surgimento de novos trabalhos que respondam a outros questionamentos ligados a relação sujeito-objeto.

Como contribuição teórica este trabalho teve a missão de agregar o ethos compartilhado como ferramenta para o entendimento de escolhas de consumo. Aliado a CCT pode auxiliar o desenvolvimento de outros trabalhos com objetos e objetivos distintos para a expansão dos conhecimentos teóricos. A contribuição prática envolve consumidores, administradores de páginas em redes sociais, marcas, fanpages e empresas de um modo geral.

A compreensão do capital social e seu papel nas relações com o consumidor, as estratégias que as marcas vem utilizando no ambiente virtual, o entendimento da relação da cultura com o consumo são fontes de informações para que as organizações tomem decisões pautadas em critérios que levem aos resultados esperados.

Como limitação da pesquisa apontamos a impossibilidade de contatar o administrador da página para fazer uma relação do ethos dele com o dos seguidores. Pela não realização da entrevista não pode-se avaliar e compreender melhor os indícios de influência digital realizada pela persona dele, conforme apontados nas entrevistas. Tampouco, pode-se conhecer a intencionalidade ou não das postagens, postura e discurso realizados por ele. Contudo, estas questões propiciam a realização de futuras pesquisas que possam debruçar-se sobre estes pontos 
em específico.

\section{Referências}

ADERALDO, L D. Do estabelecimento de identidades culturais na Internet: uma análise dos traços de "cearensidade" no personagem Suricate Seboso. Temática, v. 12, n. 3, 2016.

ALBINO, J. C. A. et al. Cultura de consumo, comunicação e práticas de branding: aproximações possíveis. Encontro de Marketing do ANPAD, v. 4, 2010.

AMOSSY, R. (Org.). Imagens de si no discurso: a construção do ethos. Trad. D. F. da Cruz, F. Komesu, S. Possenti. São Paulo: Contexto, 2005.

ARNOULD, E. J.; THOMPSON, C. J. Consumer culture theory (CCT): Twenty years of research. Journal of Consumer Research, v. 31, n. 4, p. 868-882, 2005.

ARNOULD, E. J; THOMPSON, C. J. Consumer culture theory (and we really mean theoretics): dilemmas and opportunities posed by an academic branding strategy. In: BELK, R. W.; SHERRY, J. F. Consumer culture theory. Oxford: Elsevier, 2007.

BARBOSA, L. Sociedade de consumo. Rio de Janeiro: Jorge Zahar Ed., 2004.

BARDIN, L. Análise de Conteúdo. São Paulo: Edições 70, 2011.

BEAL, B.; CROSSET, T. The use of subculture and subworlds in ethnography works on sports. Sociology of Sports Journal, 1997.

BELK, R. W. Possessions and the extended self. Journal of Consumer Research, v. 15, n. 2, p. 139-168, 1988.

CAREGNATO, R. C. A.; MUTTI, R. Pesquisa qualitativa: análise de discurso versus análise de conteúdo. Texto Contexto Enferm., v. 15, n. 4, p. 679-84, 2006.

CARRERA, F. Instagram no Facebook: uma reflexão sobre ethos, consumo e construção de subjetividade em sites de redes sociais. Animus. Revista Interamericana de Comunicação Midiática, v. 11, n. 22, 2012.

CASOTTI, L. M.; SUAREZ, M.l C. Dez anos de Consumer Culture Theory: delimitações e aberturas. RAE Revista de Administração de Empresas, v. 56, n. 3, p. 353-359, 2016.

DENZIN, N. K. e LINCOLN, Y. S. Paradigmatic controversies, contradictions, and emerging confluences. In: N. K. Denzin e Y. S. Lincoln (eds.). The Sage Handbook of qualitative research. 3.ed. Thousand Oaks: Sage Publications, 2005.

DUARTE, R. Pesquisa qualitativa: reflexões sobre o trabalho de campo. Cadernos de pesquisa, v. 115, n. 1, p. 139-154, 2002.

FACEBOOK. Facebook para empresas. $45 \%$ da população brasileira acessa o Facebook mensalmente. Disponível em: <https://www.facebook.com/business/news/BR-45-da-populacao-brasileira-acessa-o-Facebookpelo-menos-uma-vez-ao-mes>. Acesso em: 2 jun. 2015.

FERNANDES, E. G. O papel do ethos prévio nos discursos de posse de Lula. Signo, v. 35, n. 59, p. 274-289, 2011.

FONTANELLA, B. J. B. et al. Amostragem em pesquisas qualitativas: proposta de procedimentos para constatar saturação teórica. Caderno de Saúde Pública, v. 27, p. 389-394, 2011.

FROCHTENGARTEN, F. A memória oral no mundo contemporâneo. Estudos Avançados, v. 19, n. 55, p. 367376, 2005.

GAIÃO, B. F. de S.; SOUZA, I. L. de; LEÃO, A. L. M. de S. Consumer culture theory (CCT) já é uma escola de pensamento em marketing?. RAE-Revista de Administração de Empresas, v. 52, n. 3, p. 330-344, 2012.

GOFFMAN, E. A representação do eu na vida cotidiana. Trad. Maria Célia Santos Raposo. Petrópolis: Vozes, 1985

HOLT, D. B. Poststructuralist Lifestyle Analysis. Journal of Consumer Research, Chicago, vol. 23, n. 4, p. 326350, Mar. 1997.

LINCOLN, Y. S.; GUBA, E. G. Controvérsias paradigmáticas, contradições e confluências emergentes. In: 
DENZIN, N. K.; LINCOLN, Y.S. (org.). O planejamento da pesquisa qualitativa: teorias e abordagens. 2.ed. Porto Alegre: Artmed, 2006.

MCCRACKEN, G. Cultura e consumo: novas abordagens ao caráter simbólico dos bens e das atividades de consumo. Rio de Janeiro: Mauad, 2003.

MCCRACKEN-FLESHER, C. Culture, Nation, and the New Scottish Parliament. Lewisburg : Bucknell University Press, 2007.

OLIVEIRA, L. A. et al. "Mate um nordestino afogado": análise crítica de um artigo da revista época. Linguagem em (Dis)curso, v. 11, n. 2, p. 7, 2011.

PAIVA JÚNIOR, F. G. de; SOUZA, A. L. M. de; MELLO, S. C. B. de. Validade e confiabilidade na pesquisa qualitativa em administração. Revista de Ciências da Administração, v. 13, n. 31, p. 190, 2011.

PALÁCIOS, A. J. As marcas na pele, as marcas no texto: sentidos de tempo, juventude e saúde na publicidade de cosméticos, em revistas femininas durante a década de 90. 2004. Tese (Doutorado em Comunicação e Cultura Contemporâneas) - Universidade Federal da Bahia, 2004.

PEREIRA, M. Éthos compartilhado e o consumo da reputação do outro no Facebook. São Paulo: XXXIX Congresso Brasileiro de Ciências da Comunicação, 2016.

PINTO, M. de R. et al. Consumer Culture Theory (CCT) no Contexto das Experiências de Consumo de Serviços: Em Busca de uma Agenda de Pesquisas. Revista Interdisciplinar de Marketing, v. 5, n. 2, p. 49-68, 2016.

PINTO, M. de R.; LARA, J. E. As experiências de consumo na perspectiva da teoria da cultura do consumo: identificando possíveis interlocuções e propondo uma agenda de pesquisa. Cadernos EBAPE. BR, v. 9, n. 1, p. 37-56, 2011.

RECUERO, R. Curtir, compartilhar, comentar: trabalho de face, conversação e redes sociais no Facebook. Verso e Reverso, v. 28, n. 68, p. 117-127, 2014.

RIBEIRO, J. C. Um olhar sobre a sociabilidade no ciberespaço: aspectos sócio-comunicativos dos contatos interpessoais efetivados em uma plataforma interacional on-line. 2003. Tese (Doutorado em Comunicação e Cultura Contemporâneas) - Programa de Pós-graduação em Comunicação e Cultura Contemporâneas, Faculdade de Comunicação, Universidade Federal da Bahia, Salvador, 2003.

SACCOL, Amarolinda Zanela. Um retorno ao básico: compreendendo os paradigmas de pesquisa e sua aplicação na pesquisa em administração. Revista de Administração da UFSM, v. 2, n. 2, p. 250-269, 2010.

SALES, J. V. Esfera pública no Facebook: o caso da página Nação Nordestina. Natal - RN: XVII Congresso de Ciências da Comunicação na Região Nordeste, 2015.

SCHOUTEN, J. W.; MCALEXANDER, J. H. Subcultures of consumption: an ethnography of the new bikers. Journal of consumer research, 1995.

SEGABINAZZI, R. C. Subculturas e cultura de consumo: diferenciações e uma agenda de pesquisa para o Brasil. International Journal of Business Marketing, v. 1, n. 1, p. 53-60, 2015.

SILVA, C. R.; GOBBI, B. C.; SIMÃO, A. A. O uso da análise de conteúdo como uma ferramenta para a pesquisa qualitativa: descrição e aplicação do método. Organizações Rurais \& Agroindustriais, v. 7, n. 1, 2011.

SLATER, D. Cultura do consumo e modernidade. São Paulo: Nobel, 2002.

SOLOMON, M. R. Consumer behavior: buying having and being. New Jersey: Prentice Hall, 2004.

O comportamento do consumidor: comprando, possuindo e sendo. Porto Alegre: Bookman, 2011.

SOUZA, Ildenberg L. et al. Uma Abordagem Alternativa para a Pesquisa do Consumidor: Adoção da Consumer Culture Theory (CCT) no Brasil. Alcance, v. 20, n. 3, p. 383-399, 2013.

VERGARA, S. C. Métodos de pesquisa em administração. 5. ed. São Paulo: Atlas, 2012.

ZANELLA, L. C. H. Metodologia de estudo e de pesquisa em administração. Florianópolis: Departamento de Ciências da Administração/UFSC; Brasília: CAPES; UAB, 2009. 